\title{
Pineal gland calcification and defective sense of direction
}

\author{
C R BAYLISS, N L BISHOP, R C FOWLER
}

\begin{abstract}
Calcification of the pineal gland is shown to be closely related to defective sense of direction. In a tricentre prospective study of 750 patients lateral skull radiographs showed that 394 had calcified pineal glands. Sense of direction was assessed by subjective questioning and objective testing and the results noted on a scale of $0-10$ (where 10 equals perfect sense of direction). The average score for the 394 patients with pineal gland calcification was 3.7 (range 0-8), whereas the 356 patients without pineal gland calcification had an average score of 7.6 (range 2-10). This difference was highly significant $(\mathbf{p}<0.01)$. A smaller parallel study in pigeons showed that pineal calcification also leads to a reduction in homing abilities.

The findings suggested that the pineal gland plays an important part in directional sense and that damage to the gland, as indicated by calcification, causes defective sense of direction -perhaps by altering the intrinsic intracranial electromagnetic environment and thus affecting the magnetite response mechanism.
\end{abstract}

\section{Introduction}

Little is known about the function of the pineal gland. ${ }^{1}$ Its proximity to the surface of the skin in primitive animals forms the basis of its title, "the third eye." It has been the focus of superstition in many native cultures and has been ascribed many magic properties. More recently René Descartes called the pineal gland "the seat of the soul." Its association with seasonal and diurnal rhythms and its function of secreting melatonin are well known. ${ }^{2}$ Little importance has been attributed to its propensity to calcify, although in the general population $53 \%$ of lateral skull radiographs show a calcified pineal. In most patients the calcification does not appear before late adolescence or early adult life. Most elderly patients (83\%) have calcified pineals. ${ }^{3}$ Calcification of the pineal gland has hitherto been considered to be a physiological phenomenon, although it may occur in pineal tumours (usually teratomas). ${ }^{4}$

This project was stimulated by the observation that three teenage boys, injured when they lost their way on Dartmoor, had calcified pineal glands on examination of lateral skull radiographs (fig 1). As similar observations had been made in rescued sailors in Sussex and injured potholers in Yorkshire we decided to perform a tricentre prospective study to assess the relation between pineal calcification and sense of direction.

\section{Patients and methods}

The study comprised 750 consecutive patients ( 250 at each centre) who were referred to the $x$ ray department for skull radiography. The presence or absence of pineal calcification was assessed with good quality lateral skul radiographs. Each patient was asked to complete a questionnaire on how

Royal Devon and Exeter Hospital, Exeter

C R BAYLISS, FRCR, consultant radiologist

Royal Sussex County Hospital, Brighton

N L BISHOP, FRCR,consultant radiologist

The General Infirmary, Leeds

R C FOWLER, FRCR, consultant radiologist

Correspondence to: Dr Bayliss. they subjectively judged their sense of direction. This was scored as follows: excellent (5 points), good (4), fair (3), poor (2), bad (1), and none ( 0 ).

Without being able to look out of a window the patient was then asked to indicate the direction of his home from the $x$ ray department. The direction indicated was recorded as a compass reading, and the deviation of this

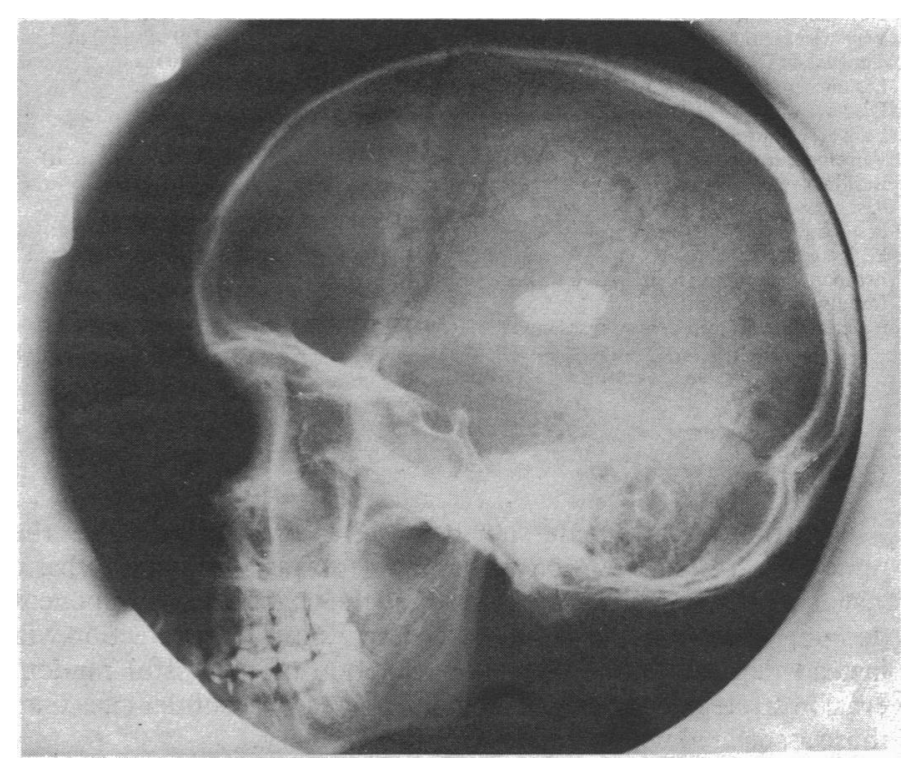

FIG 1-Lateral skull radiograph of teenage boy with calcitied pincal gland.

reading from the true direction, ascertained on a large scale local map, was recorded. This was scored as follows: $0^{\circ}-30^{\circ}\left(5\right.$ points), $30^{\circ}-60^{\circ}(4), 60^{\circ}-90^{\circ}$ (3), $90^{\circ}-120^{\circ}(2), 120^{\circ}-150^{\circ}(1)$, and $150^{\circ}-180^{\circ}(0)$. Each patient had a record made of their age, sex, presence or absence of pineal gland calcification, and total score $(0-10)$ on directional testing.

\section{Results}

Calcified pineal glands were found in 394 patients with an average sense of direction score of 3.7 (range 0-8); 356 patients did not have pineal gland calcification and had an average sense of direction score of $7 \cdot 6$ (range 2-10). The percentage of patients with calcified pineals increased with advancing age (fig 2). The average age of the 394 patients with calcified pineal glands was also higher ( $46 \cdot 8$ years) than that of those without ( $37 \cdot 3$ years).

To exclude the effect of aging alone we matched the two groups for age and sex. This produced 314 patients in each group, and the average scores for sense of direction were $4 \cdot 6$ (range $1-8$ ) and $7 \cdot 2$ (range 2-10), respectively. This difference was also highly significant $(\mathrm{p}<0.01)$.

THE PIGEON PROJECT

The pigeon's pineal weighs some $1.5 \mathrm{~g}$. This represents about $10 \%$ of the total brain weight. In the human the pineal, at $2 \mathrm{~g}$, represents less than $1 \%$ of the total brain weight. ${ }^{5}$ It has been suggested that the pineal gland plays an important part in the pigeon's homing ability. ${ }^{6}$

One of the authors (RCF) surveyed bird fanciers in his area and obtained lateral skull radiographs of some of the pigeons. None of the currently successful homing pigeons had pineal gland calcification. One pigeon, however, Northern Star (fig 3), which got lost between Buxton and Roundhay and landed exhausted on the Panamanian registered freighter Scargill's Delight off the Azores, was shown to have extensive pineal calcification (fig 4). 


\section{Discussion}

The exact function of the pineal gland has been in dispute for many years. ${ }^{7 \cdot 10}$ Our study indicates a clear relation between the pineal gland and sense of direction and suggests that this is true for both humans and animals. We also feel that our work disproves the theory that pineal gland calcification is "physiological." In all other glands calcification is related to disease (adrenal, thyroid, Cowper's, and so on). Commonly this calcification is the result of infection, infarction, haemorrhage, or tumour formation. Of these, infarction of the pineal gland would seem the most likely aetiological cause as the arterial supply via the arteria pineala magna is known to be precarious."

The exact mechanism by which the pineal gland influences directional sense is obscure. It is known that some birds, bees, bacteria, and dolphins have deposits of magnetite, a magnetic oxide of iron, in their bodies. Workers at Manchester University claim to have identified high concentrations of magnetite in man in the bones at the base of the skull around the sphenoid-ethmoid sinus complex. ${ }^{12}$ Perhaps an as yet unidentified neural or humoral pathway involving the pineal gland is interrupted when calcification occurs, thus affecting the magnetite response mechanism.

More recently workers at Sussex University (personal communication to NLB) have been using 1.5 tesla magnetic fields in a nuclear

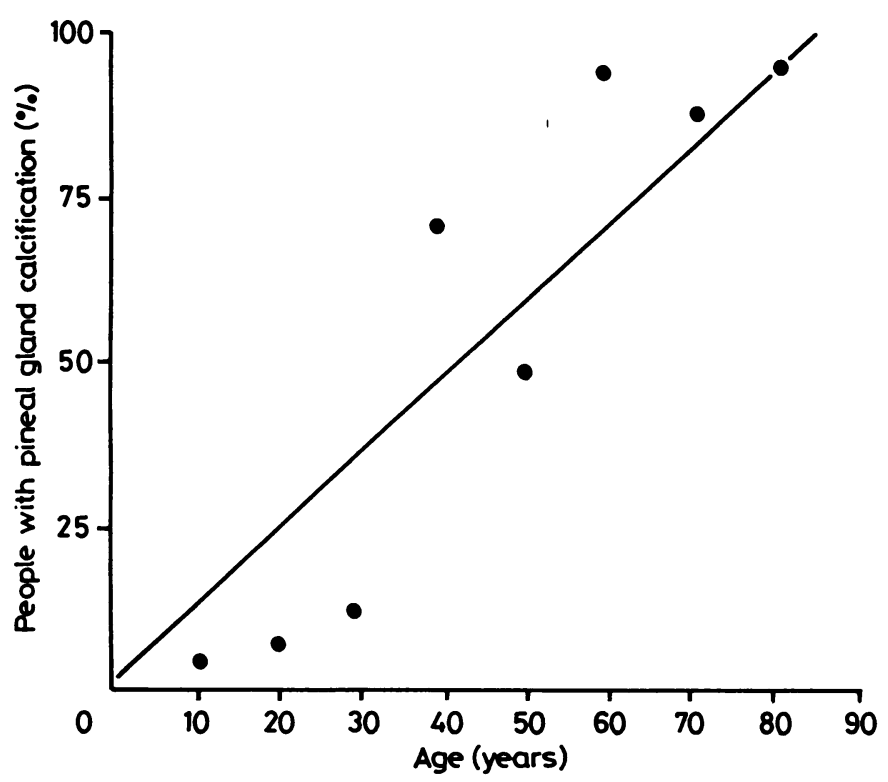

FIG 2-Increased percentage of patients with calcified pineal glands according to age.

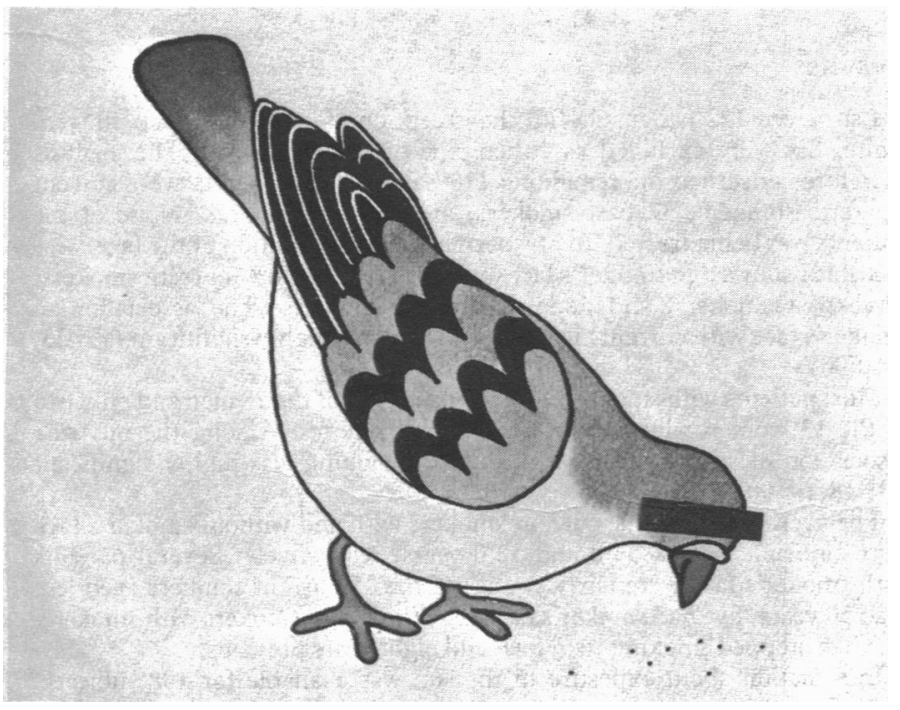

FIG 3-Northern Star, homing pigeon.

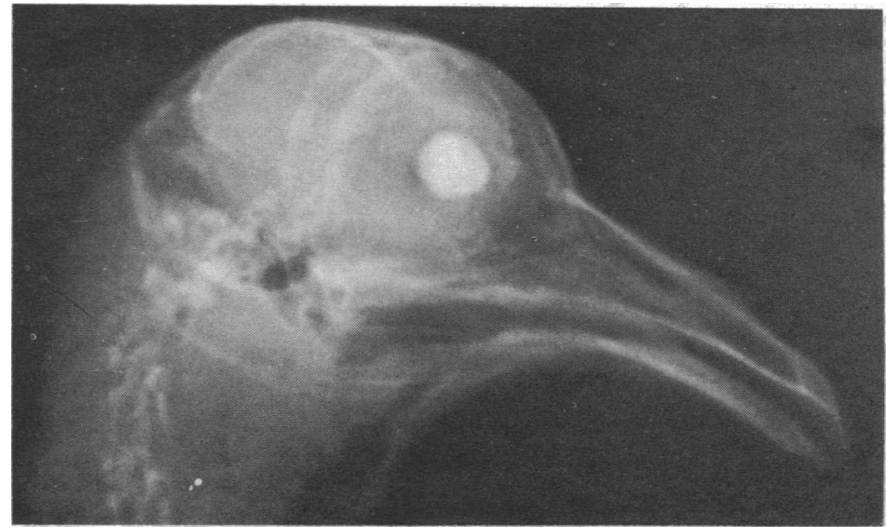

FIG 4-Lateral skull radiograph of Northern Star, shown to have extensive pineal calcification.

magnetic resonance installation in an attempt to influence the polarity of the pineal-magnetite axis in affected subjects. It seems, however, that they have not been successful so far as all their patients have been lost to follow up.

In conclusion, we think that our project has shown that the pineal gland plays a major part in the cerebral process known as sense of direction. Further work, particularly by neurobiochemical groups, is required to elucidate the precise mechanism of this process. We also think that radiological studies and postmortem examinations on schools of whales that beach themselves may well yield further valuable information about the function of the pineal gland in health and disease.

For further comment see below.

\section{References}

1 Anonymous. I am John's pineal gland. Readers Digest 1981 July: 146-52.

2 Anonymous. Timepieces and bird brains. New Scientist 1984 Oct 11.

3 Old V, Firm IN. Parameters of normality in a geriatric population. Arch Intern Med 1974;132 $101-32$.

4 Rain B, Rawn B. An analysis of intracranial calcification. Med f Milton Keynes 1981;6:4-9.

5 Stoppard M. Where there's life. Yorkshire Television 1983 Oct 17: 7 00-7 $30 \mathrm{pm}$.

6 Scott P, Matthews B. The Bo Peep syndrome in some birds. Br f Ornithol 1967;10:12016-13117.

7 Dupont P, Dubois R. Je ne comprends pas le glande pineale. Fr f Med 1934;11:101-23.

8 Dupont P, Dubois R. Je ne comprends pas le glande pineale. Fr f Med 1934;11:101-23.

8 Weiss B, Schmitd W. Was machen die Glanden pinealen? Ger f Med 1935;4:36-9.

9 Giuseppi R, Bussarelli C. Questi sono i glanduli pineali? Ital f Med 1964;7:46-61.

11 Allison D, Cumberland D, Wilkins R, Buist T, Nunnerley $\mathbf{H}$, Molyneux A, Loose H. Is ther anything that you can't embolise? British fournal of Interventional Radiology 1984;1:1-26. 12 Baker R, Mather J, Kennaugh J. Magnetic bones in human sinuses. Nature 1983;301:78.

\section{Pineal gland calcification and defective sense of direction}

\section{Comment by referee}

SIR,-I I have enjoyed reading this paper which purports to discuss the relation between pineal gland calcification and the sense of direction in man and pigeon.

In the human study the authors raise more questions than they answer. Of the three teenage boys misplaced on Dartmoor, for example, the one whose radiograph is shown has clearly lost his head. The explanation for this is not even raised in the discussion. Surely the absence of a sense of direction in these circumstances is of secondary importance? No attention has been given to the different incidence of pineal calcification in east Africa, and a notable omission from an otherwise commendable bibliography is the detailed study carried out by the German expedition of 1894 . $^{1}$

The homing ability of the pigeon is probably questioned less often than the nocturnal sense of direction of the fancier. ${ }^{2}$ The interpretation of Morning Star's behaviour is therefore open to serious doubt. To be unable to locate Roundhay is one thing but to be unable to avoid Scargill's Delight sounds like carelessness.

I regret that I cannot recommend immediate publication of this important paper but suggest that it should be reserved for the week of 1 April 1986 and the authors encouraged to be patient.

1 K Rapp, et al. Ich bin ein Vogel. Fortschr Ornitnol 1894;2:27-1063.

2 A Capp. Alcohol and the pigeon: a sociological study. J Community Medicine 1985;27:2-3. 